Short Communication

\title{
Investigation of Corrosion of A and E36 Naval Steels Using Potentiodynamic Polarization and Modified Prohesion Test
}

\author{
Buruiana Daniela Laura ${ }^{1}$, Herbei Elena Emanuela ${ }^{1}$, Ceoromila Alina Mihaela ${ }^{2}$, Busila Mariana ${ }^{1}$, \\ Trus Constantin ${ }^{3, *}$, Bogatu Nicoleta (Simionescu) ${ }^{1}$, Ghisman Viorica ${ }^{1, *}$ \\ ${ }^{1}$ Interdisciplinary Research Center in the Field of Eco-Nano Technology and Advanced Materials \\ (CC-ITI), Faculty of Engineering, "Dunarea de Jos" University of Galati, Romania \\ ${ }^{2}$ Research and Development Center for Thermoset Matrix Composites, Cross-Border Faculty," \\ Dunarea de Jos" University of Galati, Romania \\ ${ }^{3}$ Faculty of Medicine and Pharmacy," Dunarea de Jos" University of Galati, Romania \\ *E-mail: viorica.ghisman@ ugal.ro, dilconstantin@yahoo.com
}

Received: 26 April 2021 / Accepted: 26 June 2021 / Published: 10 October 2021

Our research paper aims to investigate the effects of $0.4 \%$ ammonium sulphate and $0.05 \%$ sodium chloride mixture solution (Prohesion test) on the corrosion behavior of A and E36 naval steels tested at the room temperature. The corrosion investigations have been investigated using electrochemical method such as potentiodynamic polarization curves and gravimetric method. Subsequently, the samples were subjected to morphological and compositional analyzes by scanning electron microscopy. The corrosion behavior of the A and E36 naval steels were determined from breakdown potential using potentiodynamic polarization method. The results of the electrochemical tests and gravimetric method indicate that the E36 naval steel sample has better corrosion resistance than A naval steel sample.

Keywords: Corrosion resistance; Naval steels; Potentiodynamic polarization; Electrochemical method

\section{FULL TEXT}

(C) 2021 The Authors. Published by ESG (www.electrochemsci.org). This article is an open access article distributed under the terms and conditions of the Creative Commons Attribution license (http://creativecommons.org/licenses/by/4.0/). 